\title{
Journalof Science and Engineering
}

\section{DESAIN TEBAL PERKERASAN TERHADAP VOLUME LALU LINTAS PADA KONDISI TANAH RAWA JALAN LABUHA-TOMORI BACAN KABUPATEN HALMAHERA SELATAN}

Chairul Anwarla, M. Taufik Yuda Saputrab*

a,b, Universitas Khairun, Ternate, Indonesia
Article history

Received

2 September 2018

Received in revised form

2 Oktober 2018

Accepted

5 Oktober 2018

*Corresponding author chairul.pjk@gmail.com

\section{Graphical abstract}

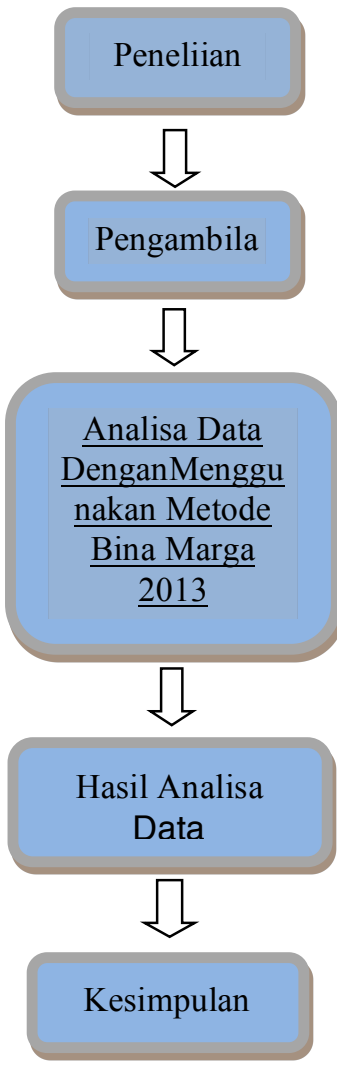

\section{Abstract}

This research was carried out on Jalan Oesman Shah on Labuha-Tomori Road. In determining flexible pavement thickness, based on the results of analysis and calculation of Pavement Thickness Design Against Traffic Volume on Swamp Conditions on the Labuha-Tomori Road Section using the Road Pavement Design Manual Number 02 / M / BM / 2013. Based on the existing plan, this Labuha-Tomori road section in South Halmahera Regency, North Maluku Province is an arterial road with 2-lane 2-way road type using the median (2/2 UD), plan width of 10 meters, width of existing traffic lane 4, 5 meters, median width of 1 meter, and planned shoulder width $2.40 \mathrm{~m}$. Based on the results of the analysis of growth rates obtained traffic growth rates of $33.066 \%$ over the life of the plan, determining the distribution factor of the lane and the capacity of the lane of lane 1 and the vehicle in the design lane taken 100\%. The equivalent load factor can be determined using the value of VDF (Vehicle Damage Factor) according to the survey results in the field. The traffic volume plan to determine the CESA4 value $=18,835,021.85$ $=18.84$ million is used for the selection of pavement types while the CESA5 value = 33,903,039.33 = 33.90 million is used to determine the type of flexible pavement based on the design chart provided in The Road Pavement Design Manual Number 02 / M / BM / 2013, is highly emphasized in terms of the improvement of subgrade, by looking at the condition of the CBR of the subgrade and CESA5 which will be received by pavement. So if the pavement CBR is $5.20 \%$ and CESA5 is 33.90 Million, the flexible pavement design is of 2 kinds in the design of pavement thickness: $A C-W C=4 \mathrm{~cm}, A C-B C=15.5 \mathrm{~cm}, C T B=15 \mathrm{~cm}, L P A$ Class $A=15 \mathrm{~cm}$, Choice of $10 \mathrm{~cm}$ and $A C-W C=4 \mathrm{~cm}, A C-B C=6 \mathrm{~cm}, A C B A S E=18 \mathrm{~cm}, L P A=30 \mathrm{~cm}$, Choice of Stock $=10 \mathrm{~cm}$, and Subgrade $=5.20 \%$

Keywords - Manual Road Pavement Design, Swamp Land, CBR

\section{Abstrak}

Penelitian ini dilakukan di Jalan Oesman Syah pada ruas jalan Labuha-Tomori. Dalam menentukan tebal perkerasan lentur, dan berdasarkan hasil analisa dan perhitungan Desain Tebal Perkerasan Terhadap Volume Lalu Lintas Pada Kondisi Tanah Rawa pada Ruas Jalan Labuha-Tomori dengan menggunakan metode Manual Desain Perkerasan Jalan Nomor 02/M/BM/2013. Berdasarkan perencanaan yang ada, pada ruas jalan Labuha-Tomori Kabupaten Halmahera Selatan Propinsi Maluku Utara ini merupakan jalan arteri dengan tipe jalan 2 lajur 2 arah dengan menggunakan median (2/2 UD), lebar rencana 10 meter, lebar jalur lalu lintas eksisting 4,5 meter, lebar median 1 meter, dan lebar bahu jalan rencana 2,40 m. Berdasarkan hasil analisa tingkat pertumbuhan yang didapat tingkat pertumbuhan lalu lintas 33,066\% selama umur rencana, Menentukan faktor distribusi jalur dan kapasitas Jumlah lajur perarah 1 dan kendaraan pada lajur desain diambil 100\%. Faktor ekivalen beban dapat ditentukan dengan menggunakan nilai VDF (Vehicle Damage Factor) sesuai dengan hasil survey dilapangan. Rencana volume lalu lintas untuk menentukan nilai $C E S A_{4}=$ 18.835.021,85 = 18,84 juta digunakan untuk pemilihan jenis perkerasan sedangkan nilai CESA $A_{5}=$ 33.903.039,33 = 33,90 juta digunakan untuk menentukan jenis perkerasan lentur berdasarkan bagan desain yang disediakan dalam Manual Desain Perkerasan Jalan Nomor 02/M/BM/2013, sangat ditekankan dalam hal perbaikan tanah dasar, dengan melihat kondisi CBR tanah dasar dan CESA5 yang akan di terima perkerasan. Maka bila CBR perkerasan sebesar 5,20\% dan CESA5 sebesar 33,90 Juta maka desain perkerasan lentur ada 2 macam dalam desain tebal perkerasan: $A C-W C=4 \mathrm{~cm}, A C-B C=15,5 \mathrm{~cm}, C T B=15 \mathrm{~cm}, L P A$ Kelas $A=15 \mathrm{~cm}$, Timbunan Pilihan $10 \mathrm{~cm}$ dan $A C-W C=4 \mathrm{~cm}, A C-B C=6 \mathrm{~cm}, A C B A S E=18 \mathrm{~cm}, L P A=$ $30 \mathrm{~cm}$, Timbunan Pilihan $=10 \mathrm{~cm}$, dan Tanah Dasar $=5,20 \%$.

Kata kunci-Manual Desain Perkerasan Jalan, Tanah Rawa, CBR

(C) 2018PenerbitFakultas Teknik Unkhair. All rights reserved 


\subsection{INTRODUCTION}

Jalan merupakan salah satu prasarana perhubungan darat yang mengalami perkembangan pesat. Oleh sebab itu pembangunan sebuah jalan haruslah dapat menciptakan keadaan yang aman bagi pengendara dan pejalan kaki yang memakai jalan tersebut. Kabupaten Halmahera Selatan khususnya di Kota Bacan saat ini mengalami pertumbuhan penduduk maupun pertumbuhan ekonomi yang sangat pesat, hal ini membuat kebutuhan masyarakat semakin melonjak, salah satunya adalah aspek transportasi darat sebagai angkutan perpindahan dari satu tempat ke tempat yang lain guna memenuhi kebutuhan hidupnya. Dari persoalan di atas, hal yang paling penting adalah layak atau tidaknya fasilitas infrastruktur transportasi darat itu sendiri.

Salah satu faktor dibangunnya sebuah jalan adalah akibat perkembangan sebuah daerah, baik itu perkembangan industri maupun perkembangan ekonomi. Akibat dari perkembangan tersebut, maka secara otomatis menyebabkan meningkatnya kepadatan lalulintas suatu daerah, baik akibat kendaraan yang masuk ke suatu daerah atau yang akan meninggalkan daerah tersebut, untuk itu sarana transportasi jalan yang dibutuhkan adalah sarana transportasi yang lancar, aman dan nyaman yaitu sarana jalan yang memenuhi persyaratan dari segi perencanaan, pembangunan, perawatan dan pengelolaannya. Dengan adanya sarana transportasi jalan ini akan dapat memperlancar arus komunikasi dan informasi antar daerah sehingga tidak ada lagi manusia yang tinggal di daerah terisolir.

Bacan Kabupaten Halmahera Selatan khususnya pada ruas jalan Labuha-Tomori terdapat srtuktur tanah dasar yang kurang baik atau kondisi tanah jelek, yakni tanah lempung, tanah gambut dan tanah rawa, di ruas jalan Labuha-Tomori sepanjang 730 M'. Sedangkan di ruas jalan ini sebagai jalan poros atau utama moda transportasi di kota tersebut. Kondisi inilah yang mendorong peniliti melakukan tinjauan terhadap struktural perkerasan jalan yang ideal.

Prasarana jalan raya mempunyai peran penting dalam pengembangan suatu wilayah. Ketersediaan konstruksi jalan yang memadai masih menjadi proyek besar di negara Indonesia ini. Beberapa wilayah masih mempunyai kondisi jalan yang memperhatinkan sehingga perlu upaya yang intensif dari pemerintah. Berdasarkan pengamatan yang dilakukan, ruas jalan Labuha-Tomori sering mengalami kerusakan jalan dari yang ringan sampai rusak berat. Pemeliharaan sudah dilakukan namun hasilnya tidak memberikan perubahan yang lebih baik. Kondisi ini diduga akibat dari tanah dasar yang tergolong jenis tanah lempung, tanah gambut dan tanah rawa. Hal ini diperkuat dengan adanya data geologi (Kabupaten Halmahera Selatan) dan tipe kerusakan pada saat musim hujan dan musiam kemarau. Selain perencanaan jalan, perkerasan jalan merupakan bagian dari perencanaan jalan yang harus direncanakan secara efektif dan efisien. Ruas jalan Labuha-Tomori merupakan jalan yang dibangun diatas tanah lempung, tanah gambut dan tanah rawah yang tentunya akan menjadi pertimbangan dalam pemilihan jenis material yang akan dipakai pada ruas jalan tersebut.

Apabila membangun konstruksi perkerasan di atas tanah dasar yang memiliki daya dukung rendah maka diperlukan teknik dan cara khusus untuk meminimalisir dampak yang diakibatkan oleh kondisi tanah tersebut. Cara yang umum dilakukan adalah dengan melakukan stabilisasi tanah dasar atau merekon struktur tanah dasar itu sendiri dengan timbunan pilihan. Salah satu parameter yang diperlukan untuk mendesain struktur perkerasan itu sendiri terletak pada nilai CBR (Califormia Bearing Ratio) tanah dasar asli atau tanah dasar yang sudah direkon.

\subsection{METODOLOGI PENELITIAN}

Data yang akan diambil dalam melalui tahapan penelitian ini terdiri dari data primer dan data sekunder sebagai berikut:

Pengumpulan data

\subsection{Data Primer}

1) Data CBR Tanah Dasar

Data CBR tanah dasar yang digunakan berasal dari hasil penyelidikan tanah lapangan dengan menggunakan alat DCP (Dynamic Cone Penetrometer).

2) Data LHR Rencana 
Data LHR Rencana yang dimaksud adalah untuk mengumpulkan data primer yang dikumpulkan yaitu data yang diperoleh langsung dengan data volume lalu lintas, tingkat pertumbuhan lalu lintas, dan data lalu lintas aktual didapat dari survei langsung pada ruas

2.2 Data Sekunder jalan Labuha-Tomori selama 7 (Tujuh) Hari.

1) Data Gambar Setuasi Lapangan

Data gambar setuasi lapangan akan diperoleh dari pihak konsultan perencana, Balai Pelaksanaan Jalan dan Jembatan wilayah IX Maluku dan Maluku Utara.

2) Tingkat Pertumbuhan Lalulintas yang diperoleh untuk desain adalah data sekunder rekapitulasi dari hasil Dinas Perhubungan Labuha Kabupaten Halmahera Selatan, sebagai Dinas Perhubungan Darat dan instansi terkait.

\subsection{HASIL DAN PEMBAHASAN}

\subsection{Gambaran Umum}

Ruas jalan Labuha - Tomori merupakan jalan yang dibangun untuk sebuah peningkatan sarana dan prasarana transportasi darat. Dan menjadi salah satu jalan penghubung menuju pusat perdagangan dan pemerintahan yang ada di Bacan Kabuten Halmaera Selatan.

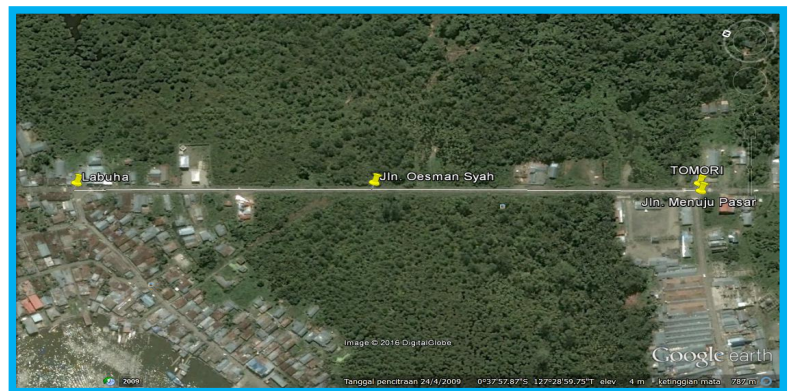

Gambar 1. Lokasi Penelitian Jln. oesman syah labuha

\subsection{Analisis Data}

Data perencanaan tebal perkerasan yang digunakan data primer berupa data lalu lintas harian rata-rata (LHR), California Bearing Ratio (CBR) berupa data DCP dan data geometrik jalan berupa jalan 2 arah dengan 2 lajur dan lebar per lajur 4,50 meter, sedangkan data sekunder berupa data pertumbuhan lalu lintas.

\subsubsection{Volume lalu lintas}

Untuk perencanaan pada Ruas Jalan ini diambil data LHR pada Ruas Jalan Labuha-Tomori.

Tabel 1. Data Survey LHR Labuha - Tomori Tahun 2016.

\begin{tabular}{|c|c|c|c|}
\hline NO & Jenis Kendaraan & Total LHR & $\begin{array}{c}\text { Kendaraan Rata-rata/ } \\
\text { 7Hari } \\
\end{array}$ \\
\hline 1 & Sepeda Motor (Kendaraan) & 25408 & 3629,71 \\
\hline 2 & Sedan, Jeep, Carry, Kijang (Kendaraan) & 8619 & 1231,29 \\
\hline 3 & Bus Kecil (Kendaraan) & 3 & 0,43 \\
\hline 4 & Pick Up/Mobil Box (Kendaraan) & 1671 & 238,71 \\
\hline 5 & $\begin{array}{l}\text { Truk Ringan/Sedang } \quad(2 \quad \text { As/Tangki) } \\
\text { (Kendaraan) }\end{array}$ & 1323 & 189,00 \\
\hline 6 & Truck Berat (3 As) (Kendaraan) & 0 & 0,00 \\
\hline & Total & 37024 & 5289,14 \\
\hline
\end{tabular}

Sumber.Survey Langsung Labuha-Tomori Kabupaten Halmahera Selatan 


\subsubsection{Data CBR (California Bearing Ratio) Tanah Dasar}

Pengujian dilakukan menggunakan alat DCP dengan ukuran konus 300. Jarak pengambilan data antar titik yaitu $25 \mathrm{~m}$, sehingga data yang didapatkan seperti pada nilai CBR yang dapat ditentukan dengan rumus sebagai berikut:

Contoh perhitungan untuk STA $00 \pm 000$ dengan nilai penetrasi $243 \mathrm{~mm}$

$\log _{10} \mathrm{CBR}=2.503-\left(1.15 * \log _{10}(243)\right)$

$\log _{10} \mathrm{CBR}=(2.503-2,743)$

$\mathrm{CBR}=10^{\wedge 0.240}=1,737 \%$

Dari nilai tersebut dibuatlah grafik CBR untuk menentukan nilai CBR segmen 90\% dapat dilihat pada Grafik 1.

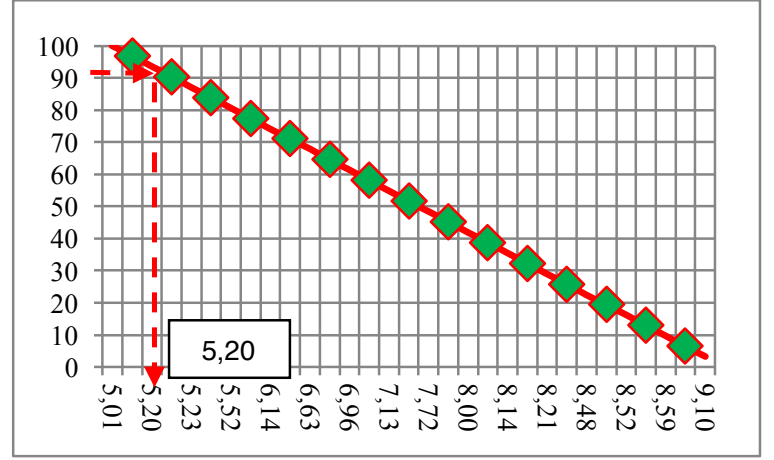

Gambar 1. Grafik CBR Segmen

Dari grafik 1. didapat nilai CBR segmen sebesar 5,20\%

3.2 Analisa Konstruksi Perkerasan Lentur (Flexible Pavement) Dengan Metode Bina Marga 2013

1) Dasar Desain Ruas Jalan

\subsection{Penampang Melintang Jalan}

Berdasarkan perencanaan yang ada, ruas jalan Labuha-Tomori Kabupaten Halmahera Selatan Propinsi Maluku Utara ini merupakan jalan arteri dengan tipe jalan 2 lajur 2 arah dengan menggunakan median (2/2 UD), dengan lebar rencana 10 meter, lebar jalur lalu lintas eksisting 4,5 meter, lebar median 1 meter, dan lebar bahu jalan rencana 2,40 m. Pada Hasil Skripsi ini, direncanakan ruas jalan arteri yang nantinya digunakan sebagai jalan nasional yang menghubungkan Babang Kabupaten Halmahera Selatan.

3.4 Penentuan Kemiringan Melintang Normal Dan Maksimum

Kemiringan melintang normal ruas jalan rencana ditetapkan sebesar $2 \%$ guna mengalirkan air untuk saluran samping atau tepi jalan.

2) Parameter Data Perencanaan

a. Menentukan Umur Rencana

b. Faktor pertumbuhan lalu lintas

$$
\begin{aligned}
& R=\frac{(1+0,01 \times 5)^{20}-1}{0,01 \times 5} \\
& R=\frac{\left(\left((1+(0,01 * 5))^{20}\right)-1\right)}{0,01 * 5} \\
& R=\frac{1,653}{0,05} \\
& R=33,066 \%
\end{aligned}
$$


Berdasarkan hasil analisa diatas didapat tingkat pertumbuhan lalu lintas 33,066\% selama umur rencana. Nilai ini digunakan untuk menghitung komulatif beban sumbu standar ekivalen selama umur rencana (CESA4).

c. Menentukan faktor distribusi jalur dan kapasitas lajur

Dalam menentukan faktor distribusi lajur (DL) di ambil dari Jumlah lajur perarah 1 dan kendaraan pada lajur desain diambil $100 \%$

d. Faktor ekivalen beban

Faktor ekivalen beban dapat ditentukan dengan menggunakan nilai VDF (Vehicle Damage Factor).

Tabel 3. Klasifikasi Kendaraan dan Nilai VDF

\begin{tabular}{|c|c|c|c|c|}
\hline \multirow{2}{*}{ Jenis Kendaraan } & \multirow{2}{*}{ Klasifikasi } & \multirow{2}{*}{$\begin{array}{l}\text { Konfigurasi } \\
\text { Sumbu }\end{array}$} & \multicolumn{2}{|c|}{ Faktor Ekivalen Beban } \\
\hline & & & ( VDF 4 ) & $($ VDF 5) \\
\hline Sepeda Motor (Kendaraan) & 1 & 1.1 & 0,00 & 0,00 \\
\hline $\begin{array}{l}\text { Sedan/Angkot/Pickup/s tation } \\
\text { Wagon (Kendaraan) } 1+1\end{array}$ & 2.3 .4 & 1.1 & 0,00 & 0,00 \\
\hline Bus Kecil (Kendaraan) $1+2$ & $5 a$ & 1.2 & 0,30 & 0,20 \\
\hline $\begin{array}{l}\text { Pick Up/Mobil Box } \\
\text { (Kendaraan) } 1+2\end{array}$ & 6.1 & 1.2 & 0,30 & 0,20 \\
\hline $\begin{array}{c}\text { Truk Ringan/Sedang (2 } \\
\text { As/Tangki) (Kendaraan) } 1+22\end{array}$ & 6.2 & 1.2 & 0,80 & 0,80 \\
\hline
\end{tabular}

Sumber : Manual Desain Perkerasan Jalan 02/M/BM/2013

e. Rencana volume lalu lintas

Untuk menentukan nilai $\mathrm{ESA}_{4}$ (lintasan sumbu standar ekivalen untuk 1 hari), dapat digunakan rumus:

$E S A_{4}=\left(\sum\right.$ jenis kendaraan $\left.\left.L H R T \times V D F\right) \times D D\right)$

Contoh perhitungan untuk jenis kendaraan (Truk Ringan/Sedang (2 As/Tangki)

(Kendaraan) $1+22)$ :

$\mathrm{ESA}_{4}=(1323 \times 0,80) \times 1=1.058,4$

Untuk jenis kendaraan yang lain dengan menggunakan rumus yang sama.

Tabel 4. Menentukan Nilai ESA4

\begin{tabular}{ccccc}
\hline Jenis Kendaraan & LHRT & VDF 4 & DL & ESA4 \\
\hline $\begin{array}{c}\text { Kendaraan Ringan 1+1 } \\
\text { Sedan/Angkot/Pickup/s tation Wagon } \\
\text { (Kendaraan) 1+1 }\end{array}$ & 25408 & 0,00 & 1 & 0 \\
$\begin{array}{c}\text { Bus Kecil (Kendaraan) 1+2 } \\
\text { Pick Up/Mobil Box (Kendaraan) 1+2 }\end{array}$ & 16619 & 0,00 & 1 & 0 \\
$\begin{array}{c}\text { Truk Ringan/Sedang (2 As/Tangki) } \\
\text { (Kendaraan) 1+22 }\end{array}$ & 1323 & 0,30 & 1 & 0,9 \\
\hline$\quad$ ESA 4 & & 0,30 & 1 & 501,3 \\
\hline
\end{tabular}

Sumber : Manual Desain Perkerasan Jalan 02/M/BM/2013 
f. Menghitung nilai CESA4

Untuk menghitung nilai $\mathrm{CESA}_{4}$, diawali dengan menghitung nilai $\mathrm{ESA}_{4}$ (Equivalent Standart Axle). Dengan menggunakan rumus, setelah didapat nilai $\mathrm{ESA}_{4}$, dilanjutkan perhitungan dengan rumus, Untuk mendapatkan nilai $\mathrm{CESA}_{4}$.

$\operatorname{CESA}_{4}=E S A \times 365 \times R$

Dimana :

$\mathrm{CESA}_{4}=$ Kumulatif beban sumbu standar ekivalen selama umur rencana

$E S A_{4}=$ Lintasan sumbu standar ekivalen untuk 1 (satu) hari

$L H R T=$ Lintas harian rata-rata tahunan untuk jenis kendaraan tertentu

$D D \quad=$ Faktor distribusi arah

$R \quad=$ Faktor pertumbuhan lalu lintas

Contoh perhitungan untuk jenis kendaraan Truk Ringan/Sedang ( 2 As/Tangki)

(Kendaraan) 1+22) :

$\mathrm{CESA}_{4}=1.560,6 \times 365 \times 33,066=18.835 .021,85$

Untuk jenis kendaraan yang lain dengan menggunakan rumus yang sama, dapat dilihat pada tabel 5 .

Tabel 5. Menentukan Nilai CESA 4

\begin{tabular}{ccccc}
\hline Jenis Kendaraan & R $(\%)$ & JLH Hari & ESA 4 & CESA4 \\
\hline $\begin{array}{c}\text { Kendaraan Ringan 1+1 } \\
\text { Sedan/Angkot/Pickup/s tation } \\
\text { Wagon (Kendaraan) 1+1 }\end{array}$ & 33,066 & 365 & 0,00 & 0,000 \\
Bus Kecil (Kendaraan) 1+2 & 33,066 & 365 & 0,00 & 0,000 \\
Pick Up/Mobil Box (Kendaraan) & 33,066 & 365 & 0,9 & $10.862,181$ \\
$\begin{array}{c}\text { 1+2 } \\
\text { Truk Ringan/Sedang (2 }\end{array}$ & 33,066 & 365 & 1058,4 & $12.773 .924,86$ \\
\hline As/Tangki) (Kendaraan) 1+22 CESA 4 & & & $18.835 .021,85$ \\
\hline \multicolumn{2}{c}{ C }
\end{tabular}

Sumber : Manual Desain Perkerasan Jalan 02/M/BM/2013

Dari Tabel 5. didapat nilai komulatif beban sumbu standar selama umur rencana $\left(\mathrm{CESA}_{4}\right)$ $=18.835 .021,85$ ESAL

g. Tentukan nilai Traffic Multiplier (TM)

Nilai TM kelelahan lapisan aspal (TM lapisan aspal) untuk kondisi pembebanan yang berlebih di Indonesia adalah berkisar 1,8-2. Nilai yang akurat berbeda-beda tergantung dari beban berlebih pada kendaraan niaga didalam kelompok truk. Diambil nilai TM yang terkecil $\mathrm{TM}=1,8$ karena merupakan jalan dengan lalulintas rendah.

h. Hitung Nilai $\mathrm{CESA}_{5}$

Nilai CESA $\mathrm{C}_{5}$ dapat dihitung dengan menggunakan rumus.

$\operatorname{CESA}_{5}=\left(T M \times C E S A_{4}\right)$

Dimana : 
CESA $=$ Cumulative Equivalent Standard Axles

$T M=$ Traffic Multiplier

$\mathrm{CESA}_{5}=1,8 \times 18.835 .021,85$

$\mathrm{CESA}_{5}=33.903 .039,33 \mathrm{ESAL}$

Nilai $\mathrm{CESA}_{4}=18.835 .021,85=18,84$ juta digunakan untuk pemilihan jenis perkerasan sedangkan nilai $\mathrm{CESA}_{5}=33.903 .039,33=33,90$ juta digunakan untuk menentukan jenis perkerasan lentur berdasarkan bagan desain yang disediakan dalam Manual Desain Perkerasan Jalan Nomor 02/M/BM/2013

i. Pemilihan Jenis Perkerasan

Untuk memilih jenis perkerasan akan bervariasi sesuai dengan estimasi lalu lintas, umur rencana, untuk pemilihan umur rencana 20 tahun dengan menggunakan nilai $\mathrm{CESA}_{4}=$ 18,84 juta dari tabel Nilai $\mathrm{CESA}_{4}$ berada diantara 10-30 sehingga digunakan jenis perkerasan AC WC modifikasi atau SMA modifikasi dengan CTB (pangkat 5).

Tabel 6 Pemilihan Jenis Perkerasan

\begin{tabular}{|c|c|c|c|c|c|c|}
\hline \multirow{2}{*}{ Struktur Perkerasan } & \multirow{2}{*}{ desain } & \multicolumn{5}{|c|}{$\begin{array}{c}\text { ESA20 tahun (juta) } \\
\text { (pangkat 4 kecuali disebutkan lain) }\end{array}$} \\
\hline & & $0-0,5$ & $0,1-4$ & $\frac{4-10}{4-10}$ & $10-30$ & $>30$ \\
\hline $\begin{array}{l}\text { Perkerasan kaku dengan lalu } \\
\text { lintas berat }\end{array}$ & 4 & & & 2 & 2 & 2 \\
\hline $\begin{array}{l}\text { Perkerasan kaku dengan lalu } \\
\text { lintas rendah (desa dan } \\
\text { daerah nerkotaan) }\end{array}$ & $4 \mathrm{~A}$ & & 1,2 & & & \\
\hline $\begin{array}{l}\text { AC WC modifikasi atau SMA } \\
\text { dengan CTB (panghat 5) }\end{array}$ & 3 & & & & 2 & \\
\hline$A C$ dengan $C T B$ (pangkat 5) & 3 & & & 2 & & \\
\hline $\begin{array}{c}\text { AC tebal } \geq 100 \mathrm{~mm} \text { dengan } \\
\text { lapis pondasi berbutir } \\
\text { (pangkat 5) }\end{array}$ & $3 \mathrm{~A}$ & & & 1,2 & & \\
\hline $\begin{array}{l}\text { AC tipis atau HRS diatas lapis } \\
\text { pondasi berbutir }\end{array}$ & 3 & & 1,2 & & & \\
\hline $\begin{array}{l}\text { Burda atau Burtu dengaan LPA } \\
\text { Kelas A atau Kerikil Alam }\end{array}$ & Gambar 5 & 3 & 3 & & & \\
\hline $\begin{array}{l}\text { Lapis Poondasi Tanah Semen } \\
\text { (Soil Cement) }\end{array}$ & Gambar 6 & 1 & 1 & & & \\
\hline Perkerasan Tanpa Penutup & Gambar 7 & 1 & & & & \\
\hline
\end{tabular}

Sumber : Manual Desain Perkerasan Jalan 02/M/BM/2013

j. Menentukan desain pondasi

Dalam Manual Desain Perkerasan Jalan Bina Marga 2013 sangat ditekankan dalam hal perbaikan tanah dasar, dengan melihat kondisi CBR tanah dasar dan CESA5 yang akan di terima perkerasan. Maka bila CBR perkerasan sebesar 5,20\% dan CESA5 sebesar 33,90 Juta maka diperlukan perbaikan ditunjukkan pada Bagan Desain 2 Solusi Desain Pondasi Jalan Minimum ${ }^{3}$ Berada diantara.

Bagan Desain 2 : Solusi Desain Pondasi Jalan Minimum ${ }^{3}$

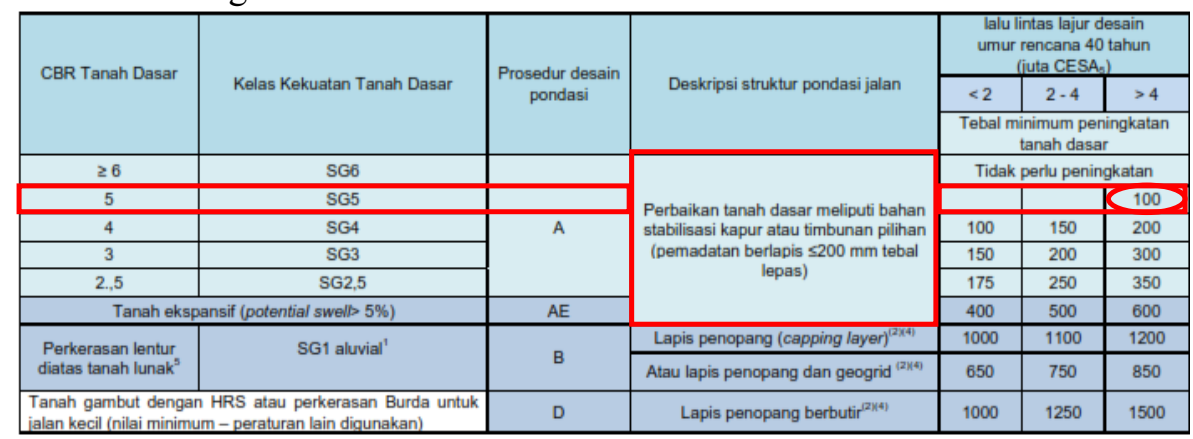

Sumber : Manual Desain Perkerasan Jalan 02/M/BM/2013

Bila CBR perkerasan sebesar 5,20\% dan CESA5 33,90 maka perlu perbaikan tanah dasar untuk menentukan tebal desain pondasi jalan. Maka yang didapat yaitu $10 \mathrm{~cm}$ untuk timbunan pilihan. 
3) Desain Perkerasan

Pada analisa ini mendeskripsikan desain seluruh lapisan diatas tanah dasar (formasi bagaian atas).

a. Struktur Perkerasan

Solusi pekerasan yang banyak dipilih yang didasarkan pada pembebanan dan pertimbangan biaya terkecil diberikan dalam Bagan Desain 3 Perkerasan Lentur.

b. Menentukan Desain Tebal Perkerasan

Tebal yang akan dihasilkan oleh Manual Desain Perkerasan Jalan Nomor 02/M/BM/2013 didapat melalui Bagan Desain 3 : Desain Perkerasan Lentur opsi biaya minimum termasuk CTB $)^{1}$ dan Alternatif Bagan Desain 3A : Desain Perkerasan Lentur-Aspal dengan Lapis Pondasi Berbutir yang telah disediakan berdasarkan CESA5 yang telah didapat. Dengan memasukan nilai $\mathrm{CESA}_{5}=33,90$ juta.

Bagan Desain 3 : Desain Perkerasan Lentur opsi biaya minimum termasuk CTB) ${ }^{1}$

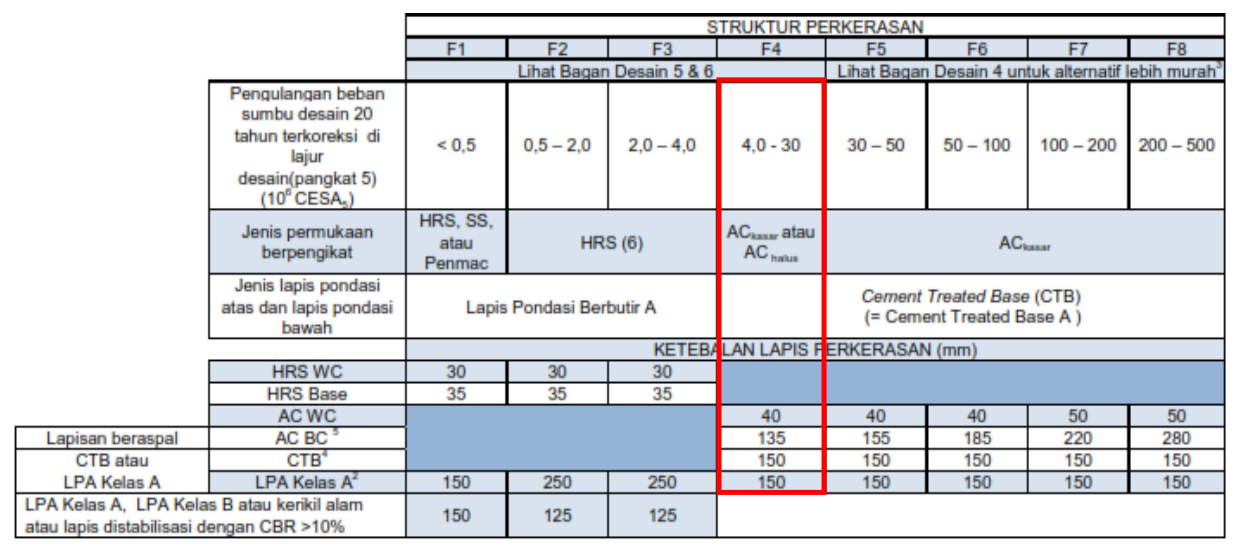

Sumber : Manual Desain Perkerasan Jalan 02/M/BM/2013

c. Menentukan Desain Perkerasan Lentur-Aspal dengan Lapis Pondasi Berbutir

Bagan Desain 3A Perkerasan Berbutir dan Pelaburan Aspal Tipis. Solusi lain dapat diadopsi untuk menyesuaikan dengan kondisi setempat tetapi disarankan untuk tetap menggunakan bagan sebagai langkah awal untuk semua desain.

Alternatif Bagan Desain 3A : Desain Perkerasan Lentur-Aspal dengan Lapis Pondasi Berbutir (Solusi untuk Reliabilitas 80\% Umur Rencana 20 Tahun)

\begin{tabular}{|c|c|c|c|c|c|c|c|c|c|}
\hline & \multicolumn{9}{|c|}{ STRUKTUR PERKERASAN } \\
\hline & FF1 & FF2 & FF3 & FF4 & FF5 & FF6 & FF7 & FF8 & FF9 \\
\hline \multicolumn{5}{|l|}{ Solusi yang dipilih } & \multicolumn{2}{|c|}{ Lihat Catatan 3} & \multicolumn{3}{|c|}{ Lihat Catatan 3} \\
\hline $\begin{array}{l}\text { Pengulangan beban } \\
\text { sumbu desain } 20 \\
\text { tahun di lajur desain } \\
\text { (pangkat } 5) \\
\left(10^{6} \mathrm{CESA}_{5}\right)\end{array}$ & $1-2$ & $2 \cdot 4$ & $4-7$ & $7 \cdot 10$ & $10-20$ & $20-30$ & $30-50$ & $50-100$ & $100-200$ \\
\hline & \multicolumn{9}{|c|}{ KETEBALAN LAPIS PERKERASAN ( $\mathrm{nm})$} \\
\hline ACWC & 40 & 40 & 40 & 40 & 40 & 40 & 40 & 40 & 40 \\
\hline $\mathrm{ACBC}$ & 60 & 60 & 60 & 60 & 60 & 60 & 60 & 60 & 60 \\
\hline AC Base & 0 & 70 & 80 & 105 & 145 & 160 & 180 & 210 & 245 \\
\hline LPA & 400 & 300 & 300 & 300 & 300 & 300 & 300 & 300 & 300 \\
\hline Catatan & 1 & 1 & 2 & 2 & 3 & 3 & 3 & 3 & 3 \\
\hline
\end{tabular}

Sumber : Manual Desain Perkerasan Jalan 02/M/BM/2013 
Maka ada 2 alternatif dalam desain tebal perkerasan lentur yaitu:

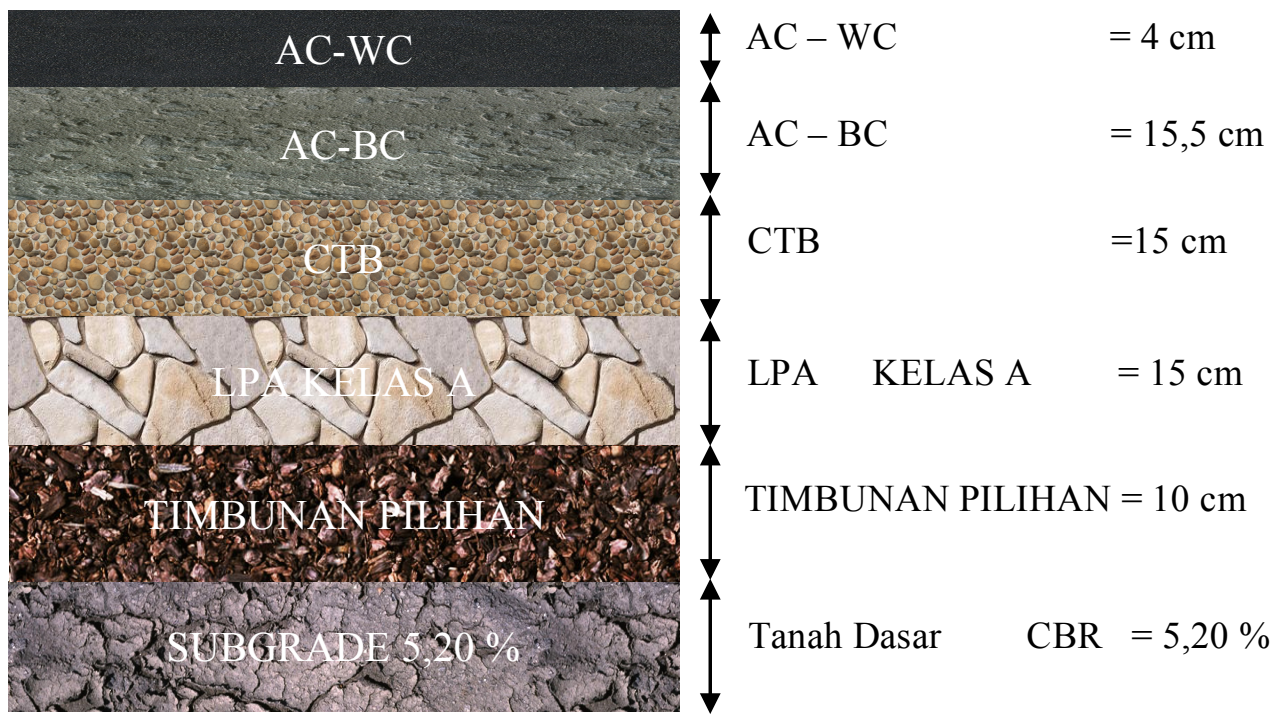

Gambar 2 Desain Perkerasan Lentur opsi biaya minimum termasuk CTB ${ }^{1}$

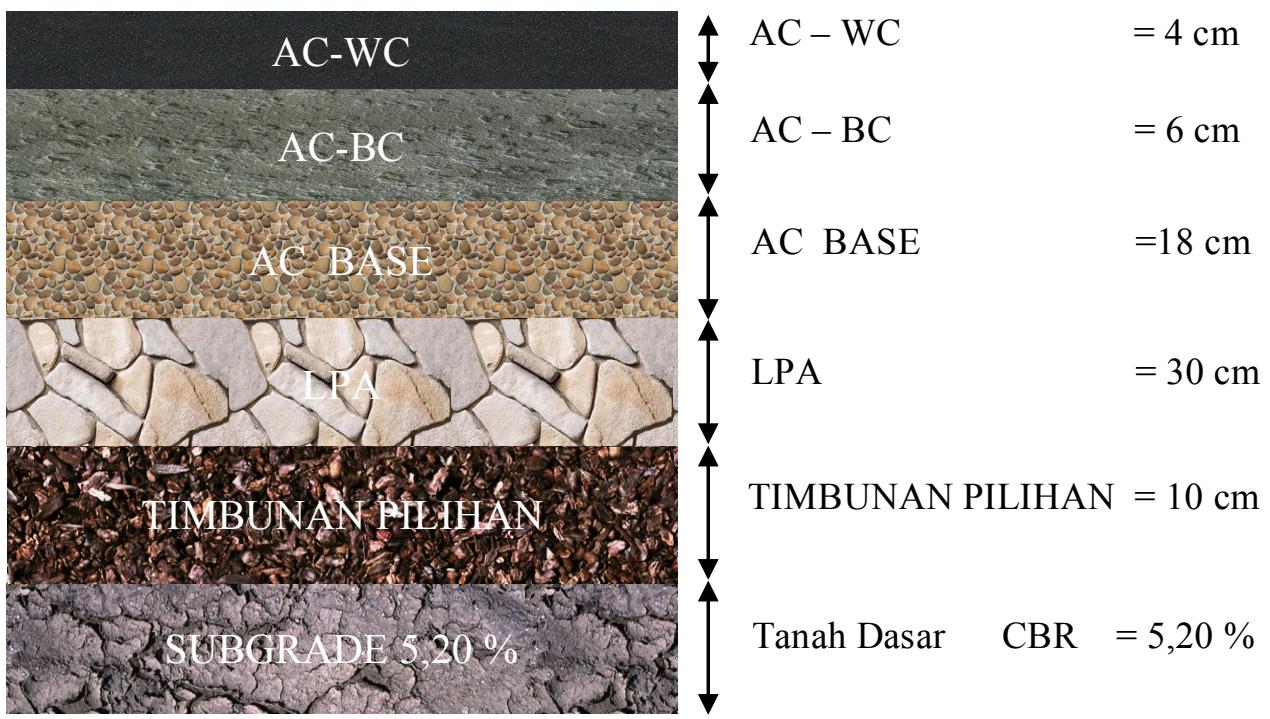

Gambar 3 Desain Perkerasan Lentur -Aspal dengan Lapis Pondasi Berbutir

4.0 Katalog Desain

Desain perkerasan dalam Manual Desain Perkerasan Jalan 02/M/BM/2013 telah memudahkan desainer untuk menentukan tebal lapis perkerasan yang didasarkan pada pembebanan pertimbangan biaya terkecil diberikan dalam desain 3 maupun 3A. Nilai CESA5yang digunakan sebesar 33.903.039,33 ESAL. Tebal lapis perkerasannya dapat dilihat pada Bagan Desain 3: Perkerasan Lentur opsi biaya minimum termasuk CTB) ${ }^{1}$ dan Bagan Desain 3A: Desain Perkerasan Lentur-Aspal dengan Lapis Pondasi Berbutir (Solusi untuk Reliabilitas 80\% Umur Rencana 20 Tahun) dapat dilihat pada Gambar 2 dan Gambar 3 di atas.

5.0 Ringkasan Tahapan Hasil Analisa Desain

1) Berdasarkan perhitungan tebal perkerasan diatas tanah dasar dengan nilai CBR 5,20\% adalah seperti yang ditunjukkan pada Gambar 2 perkerasan didesain dengan lapis penopang $10 \mathrm{~cm}$ dan penggunaan $\mathrm{CTB})^{1}$ pada lapis pondasi perkerasan. 
2) Berdasarkan Desain Perkerasan Jalan 02/M/BM/2013, dengan hasil analisa desain terhadap umur rencana dan faktor kerusakan (VDF), maka perkerasan harus didesain dengan menggunakan bagan desain 3 yaitu menggunakan struktur perkerasan AC-WC, AC-BC dan CTB. Sedangkan hasil analisa untuk tanah rawa, yaitu tanah dasar dengan $\mathrm{CBR}=5,20 \%$ (CBR $5 \%$ ), penggunaan lapis penopang perbaikan tanah dasar meliputi bahan stabilisasi kapur atau timbunan pilihan (pemadatan berlapis $\leq 200 \mathrm{~mm}$ tebal lapas) berdasarkan Bagan Desain 2 harus diambil setebal $300 \mathrm{~mm}$.

3) Jika sumber daya tidak memadai untuk mengerjakan konstruksi CTB, maka solusi yang ditunjukkan pada alternatif bagan desain 3A dapat digunakan. Lapis pondasi Agregat Kelas A digunakan sebagai pengganti CTB. Struktur perkerasan dari desain tersebut dapat dilihat pada gambar 3 .

\subsection{Kesimpulan}

Berdasarkan hasil analisis dan perhitungan pada bab sebelumnya tentang Desain Tebal Perkerasan Terhadap Volume Lalu Lintas Pada Kondisi Tanah Rawa Jalan pada Ruas Jalan Labuha-Tomori dengan metode Manual Desain Perkerasan Jalan Nomor 02/M/BM/2013, maka dapat diambil kesimpulan sebagai berikut :

Pada ruas jalan Labuha-Tomori dengan panjang $\pm 730 \mathrm{~m}$ ' dan lebar per lajur $4.50 \mathrm{~m}$, Berdasarkan data LHR didapatkan Nilai $\mathrm{CESA}_{4}=18.835 .021,85=18,84$ juta ESAL, CESA $5=$ 33.903.039,33 = 33,90 juta ESAL, nilai CBR 5,20\%, umur rencana 20 tahun untuk perkerasan lentur, dan parameter lain disyaratakan Manual Desain Perkerasan Jalan Nomor 02/M/BM/2013, diperoleh tebal perkerasan rencana berdasarkan Desain 3 : Desain Perkerasan Lentur opsi biaya minimum termasuk CTB) ${ }^{1}$ dan Alternatif Bagan Desain 3A : Desain Perkerasan Lentur-Aspal dengan Lapis Pondasi Berbutir, Maka desain perkerasan lentur ada 2 macam dalam desain tebal perkerasan yaitu:

1. $\mathrm{AC}-\mathrm{WC}=4 \mathrm{~cm}, \mathrm{AC}-\mathrm{BC}=15,5 \mathrm{~cm}, \mathrm{CTB}=15 \mathrm{~cm}, \mathrm{LPA}=15 \mathrm{~cm}$, Timbunan Pilihan 10 $\mathrm{cm}$ dan Tanah Dasar $=5,20 \%$

2. $\mathrm{AC}-\mathrm{WC}=4 \mathrm{~cm}, \mathrm{AC}-\mathrm{BC}=6 \mathrm{~cm}, \mathrm{AC} \mathrm{BASE}=18 \mathrm{~cm}, \mathrm{LPA}=30 \mathrm{~cm}$, Timbunan Pilihan $10 \mathrm{~cm}$ dan Tanah Dasar $=5,20 \%$

3.

Desain perkerasan dalam Manual Desain Perkerasan Jalan 02/M/BM/2013 telah memudahkan desainer untuk menentukan tebal lapis perkerasan yang didasarkan pada pembebanan pertimbangan biaya terkecil diberikan dalam desain 3 maupun 3A. Nilai CESA5yang digunakan sebesar 33.903.039,33 ESAL. Tebal lapis perkerasannya dapat dilihat pada Bagan Desain 3: Perkerasan Lentur opsi biaya minimum termasuk CTB) ${ }^{1}$ dan Bagan Desain 3A: Desain Perkerasan Lentur-Aspal dengan Lapis Pondasi Berbutir (Solusi untuk Reliabilitas 80\% Umur Rencana 20 Tahun) dapat dilihat pada jenis tebal perkerasan di atas sebagai berikut:

1. Berdasarkan perhitungan tebal perkerasan diatas tanah dasar dengan nilai CBR 5,20\% adalah seperti yang ditunjukkan pada Gambar 2 perkerasan didesain dengan lapis penopang $10 \mathrm{~cm}$ dan penggunaan $\mathrm{CTB})^{1}$ pada lapis pondasi perkerasan.

2. Berdasarkan Desain Perkerasan Jalan 02/M/BM/2013, dengan hasil analisa desain terhadap umur rencana dan faktor kerusakan (VDF), maka perkerasan harus didesain dengan menggunakan bagan desain 3 yaitu menggunakan struktur perkerasan AC-WC, AC-BC dan CTB. Sedangkan hasil analisa untuk tanah rawa, yaitu tanah dasar dengan CBR $=5,20 \%$ (CBR $5 \%$ ), penggunaan lapis penopang perbaikan tanah dasar meliputi bahan stabilisasi kapur atau timbunan pilihan (pemadatan berlapis $\leq 200 \mathrm{~mm}$ tebal lapas) berdasarkan Bagan Desain 2 harus diambil setebal $300 \mathrm{~mm}$.

3. Jika sumber daya tidak memadai untuk mengerjakan konstruksi CTB, maka solusi yang ditunjukkan pada alternatif bagan desain 3A dapat digunakan. Lapis pondasi Agregat Kelas A digunakan sebagai pengganti CTB. Struktur perkerasan dari desain tersebut dapat dilihat pada gambar 3 . 


\section{Referensi}

[1] Bowles, E. Joseph, 1986.”Sifat- sifat dan Geoteknis Tanah ( Mekanika Tanah),Penerbit Erlangga. Jakarta Pusat.

[2] Depertemen Pekerjaan Umum, Rancangan 3, Pedoman Bahan Konstruksi Dan Rekayasa Sipil, Cara Uji CBR Dengan Dinamic Cone Penetrometer (DCP)

[3] Ditjen P.U Bina Marga. Pedoman Penentuan Tebal Perkerasan Lentur Jalan Raya, Departemen Pekerjaan Umum, No 04/PD/BM/1974

[4] Depertemen Permukiman dan Prasarana Wilayah, Pedoman Perencanaan Tebal Perkerasan Lentur Pt T-2002-B

[5] F. Fahrizal. 2015. Perencanaan Tebal Perkerasan Lentur Menggunakan Manual Desain Tebal Perkerasan Jalan Nomor 02/M/BM/2013. Jurnal Online Institute Teknologi Nasiaonal, Teknik Sipil Itenas Agustus 2015.

[6] Kementrian Pekerjaan Umum Direktorat Jendral Bina Marga, Manual Desain Perkerasan Jalan Nomor 02/M/BM/2013.

[7] https://darmadi18.wordpress.com/2016/03/23/perubahan-konsep-desain-tebal- perkerasanjalan-raya-sesuai-pedoman-bina-marga-2011/

[8] https://documents.tips/documents/sejarah-perkerasan-jalan.html

[9] http://www.academia.edu/19302018/Tugas Perkerasan Jalan http://tekniksipil2017.blogspot.co.id/2017/02/ 